http://jurnal.unipasby.ac.id/index.php/jsbr

\title{
FAKTOR FUNDAMENTAL YANG MEMPENGARUHI HARGA SAHAM PERUSAHAAN BUMN YANG TERDAFTAR DI BEI TAHUN 2016-2018
}

Sixma Goodta Rama, Mohamad Afrizal Miradji

Universitas PGRI Adi Buana Surabaya

Sixmagoodta65@gmail.com,afrizal@unipasby.ac.id

\begin{abstract}
The purpose of this study was to determine the influence of fundamental factors on the price of shares on the Indonesia Stock Exchange (IDX). The background of this writing because there are only few companies listed on the IDX and show a decline in the Composite Stock Price Index (CSPI). This study used 39 samples from 13 state own companies (BUMN) with reporting period of 3 years. Data is used secondary data. Research writing method uses quantitative methods, where the analysis of data with classic assumption test, multiple linear regression analysis, and the coefficient of determination. While testing the hypothesis by $t$ test and $f$ test. This study shows the results of hypothesis testing with CTO and ATO significantly influence stock prices. While DAR, ROA, and PER have no significant effect on stock prices. Simultaneously the ratio of CTO, DAR, ATO. ROA, and PER signifacnly influence the stock prices of BUMN companies.
\end{abstract}

\section{Keywords : IDX, BUMN, and Stock Prices}

\section{PENDAHULUAN}

Pasar modal yang menyediakan saham di Indonesia adalah BEI (Bursa Efek Indonesia). Merupakan pasar modal terbesar dan terpercaya di negara ini. Banyaknya perusahaan-perusahaan besar yang melakukan investasi di bursa tersebut menarik banyaknya emiten maupun investor yang ingin memperjual-belikan saham guna menambah modal kerja. Tak terkecuali perusahaan BUMN (Badan Usaha Milik Negara), dimana perusahaan milik pemerintah tersebut juga melakukan investasi di BEl. Meski demikian, sesuai dengan data perusahaan yang ada di BEI. Menyatakan bahwa, hanya terdapat sedikit perusahaan BUMN yang terdaftar dari sekian banyaknya peruusahaan BUMN lainnya.

Penurunan IHSG (Indeks Harga Saham Gabungan) pada perusahaan BUMN juga terjadi akibat dari adanya investor asing yang juga melepas saham di BEI. Salah satu faktor yang mendasari penurunan IHSG adalah faktor fundamental, maka dari itu perlu adanya analisis mengenai fundamental. Jogiyanto (2017:126), Analisis Fundamental dilakukan dengan alasan untuk menghitung nilai yang ada di dalam saham yang diperoleh dari laporan keuangan. Bisa dikatakan faktor fundamentalitu sendiri akan berkaitan dengan saham.

Nor Hadi (2015:67), salah satu instrumen investasi yang paling diminati dalam pasar modal adalah saham. Tujuannya untuk mendapatkan keuntungan dan sudah pasti diikuti dengan resiko-resiko yang ada didalamnya. Karena kecenderungan tersebut perlu mental yang kuat bagi perusahaan dengan persiapan khusus sebelumnya.

Saham BUMN yang tercatat aktif terhitung sejumlah 19 saham, yang sebgaian atau seluruhnya sudah terdaftar di bei. Data tersebut telah disusun sedemikian rupa dengan kode saham yang juga telah dijabarkan didalamnya.

Berdasarkan pokok permasalahan yang diuraikan maka penuliis tertarik untuk menulis judul penelitian "Analisis Faktor Fundamental yang Mempengaruhi Harga Saham Perusahaan BUMN yang terdaftar di BEI tahun 2016-2018".

\section{Landasan Teori}

Sebagai pedoman untuk penulisan sebuah karya ilmiah, tentunya tidak akan lepas dari teori yang mendasari penelitian ini. Selain daripada itu, teori-teori terkini akan bisa memperkuat hasil penulisan. Sebab, teori merupakan suatu hal yang mutlak agar penelitian ini memiliki nilai untuk dibaca serta dipahami. Sehingga bisa berguna bagi pembaca maupun penulis. 


\section{Journal of Sustainability Business Research (JSBR)}

\section{Vol-1,Issue-1,Desember (JSBR)}

\section{E-ISSN: 2746-8607}

http://jurnal.unipasby.ac.id/index.php/jsbr

Bagi sebuah perusahaan investasi merupakan hal yang umum, bahkan hampir semua karyawan dari level bawah hingga level atas akan mengetahui akan hal ini. Hanya saja nilai dari investasi tidak bisa sepenuhnya diketahui oleh seluruh pekerja di dalam ruang lingkup perusahaan tersebut.

Kasmir dan Jakfar (2015:5), Investasi didefinisikan sebagai kegiatan dalam bidang usaha dengan jangka waktu yang lama, yang kemudian hasilnya akan digunakan untuk keperluan perusahaan. Sehingga yang dimasudkan disini adalah modal yang diinvestasikan pada hakikatnya sudah diatur saat ini agar hasilnya bisa berfungsi dimasa mendatang.

Saham termasuk dalam salah satu instrumen investasi. Dimana saham ini merupakan salah satu instrumen yang paing likuid dalam kaitannya dengan investasi. Meskipun demikian saham memiliki resiko lebih tinggi dibandingkan dengan instrumen lainnya seperti deposito dan juga obligasi. Oleh karena itu saham menjadi instrumen yang harus digerakkan oleh pemilik saham, karena akan terdapat yang namanya return saham atau tingkat pengembalian saham perusahaan.

Kasmir (2016:165), mengacu pada besaran saham yang akan dimiliki oleh pemilik, karena pada intinya pemegang saham terbesar memiliki hak untuk berkuasa pada perusahaan terkait.

Setiap perusahaan memiliki yang namanya aset atau dalam istilah umumnya harta perusahaan. Harta perushaan ini nantinya yang akan menunjang kelancaran operasional perusahaan.

Munawir (2014:30), Aset merupakan sumber daya perusahaan yang memiliki nilai yang bisa diperjual belikan dimana harga jual atau belinya telah disesuaikan dengan harga pasaran.

Pasar modal atau yang biasa disebut dengan bursa efek sangat erat kaitannya dengan perusahaanperusahaan besar. Karena pasar modal ini dapat membuat modal kerja semakin bertambah, namun tentunya dengan cara yang tepat dan efektif, serta dengan mengetahui resiko-resiko didalamnya.

Irham Fahmi (2015:34), Pasar Modal menjadi tempat dimana para investor akan memperdagangkan modal yang dimiliki dengan tujuan agar memperoleh keuntungan.

Eduardus Tandelilin (2017:26), bursa efek memiliki fungsi untuk menambah modal kkerja bagi perusahaan yang membutuhkan dana, sedangkan yang kelebihan dana justru bisa menjual kelebihan dana tersebut.

Rasio keuangan merupakan sebuah alat untuk mengukur aset-aset yang terdapat pada perusahaan. Hal ini untuk mengetahui kemampuan perusahaan dalam mengelola keuangan perusahaan, apakah sudah maksimal ataukah belum.

Kasmir (2016:104), Rasio Keuangan berarti dalam laporan keuangan terdapat komponen yang bisa dianalisis didalamnya dengan cara melakukan pembagian pada bagian-bagian komponen yang berbeda tersebut yang berupa angka.

Samryn (2015:363), Rasio Keuangan dibuat kedalam bentuk perbandingan agar lebih memiliki arti, yang mana hal ini dimaksudkan untuk mengetahui kondisi kesehatan keuangan di perusahaan.

\section{Kerangka Konseptual}

Sugiyono (2017:128), sebuah keranggka konsep harus memiliki variabel yang jelas dan berlandaskan teori. Berikut adalah kerangka konseptual yang akan disajikan dalam bentuk gambar:

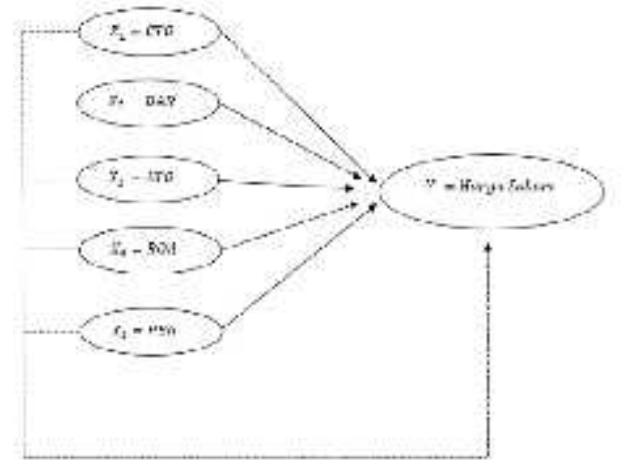

Gambar 1. Kerangka Konseptual

Keterangan :

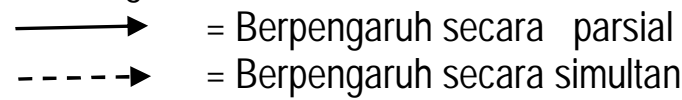




\section{Journal of Sustainability Business Research (JSBR)}

\section{Vol-1,Issue-1,Desember (JSBR)}

\section{E-ISSN: 2746-8607}

\section{Hipotesis}

http://jurnal.unipasby.ac.id/index.php/jsbr

Hipotesis merupakan dugaan hasil yang akan kita peroleh. Maka dari itu sifatnya sementara, karena hipotesis ini akan dianggap sedemikian rupa hingga pada saat hasil penelitian bisa membuktikan apakah hipotesis tersebut benar atau tidak.

Dalam penelitian ini terdapat setidaknya 6 hipotesis, yakni sebagai berikut:

$\mathrm{H} 1$ = Terdapat pengaruh CTO terhadap harga saham perusahaan BUMN

$\mathrm{H} 2=$ Terdapat pengaruh DAR terhadap harga saham perusahaan BUMN

H3 = Terdapat pengaruh ATO terhadap harga saham perusahaan BUMN

$\mathrm{H} 4=$ Terdapat pengaruh ROA terhadap harga saham perusahaan BUMN

$\mathrm{H} 5=$ Terdapat pengaruh PER terhadap harga saham perusahaan BUMN

H6 = Terdapat pengaru CTO, DAR, ATO, ROA, dan PER terhadap harga saham perusahaan BUMN.

\section{METODE}

\section{Rancangan Penelitian}

Indriantoro dan Supomo (2018:26), Rancangan Penelitian menjadi dasar sebelum penelitian dilakukan, dimana agar sebuah penelitian bisa dilakukan secara terarah sesuai dengan rencana yang sudah dibuat sebelumnya.

Dalam penelitian ini menggunakan metode kuantitatif. Populasi dari penelitian berasal dari perusahaan yang terdaftar di BEI tahun 2016-2018, sedangkan sampel adalah perusahaan BUMN yang terdaftar di BEI tahun 2016-2018. Analisa data dengan cara dilakukan pengujian statistik yakni metode regresi berganda dan koefisien determinasi. Sedangkan pengujian hipotesis dilakukan dengan memakai uji t dan uji f.

\section{Populasi, Sampel, dan Teknik Pengambilan Sampel}

Sugiyono (2017:61), Populasi harusnya memliki cakupan yang luas bahkan tak terbatas. Hanya saja hal tersebut selanjutnya bisa diteliti menggunakan sampel yang bisa menentukan hasil sesuai dengan jenis serta teknik sampling yang dipakai.

Populasi yang saya teliti adalah perusahaan BUMN yang terdaftar di BEl tahun 2016-2018. Karena sesuai dengan teori bahwa populasi tersebut cakupannya luas dan memiliki karakteristik tertentu yakni perusahaan yang menanamkan modal, terutama saham di BEl.

Sugiyono (2017:62), Sampel merupakan sebagian kecil dari keseluruhan populasi, yang mana akan dijadikan bahan penelitian dan nantinya dianalisis serta disimpulkan untuk memperoleh data yang valid. Sampel juga dapat diartikan sebagai pengambulan contoh dalam konteks penelitian.

Sampel yang saya teliti adalah perusahaan BUMN yang terdaftar di BEI tahun 2016-2028. Sehingga dari keseluruhan perusahaan yang terdaftar di BEI hanya diambil perusahaan BUMN saja yakni sebanyak 39 sampel perusahaan.

Margono (2014:125), Teknik sampling digunakan untuk menentukan sampel sesuai dengan jumlahnya, artinya sampel ini seperti mewakili data penelitian dari sejumlah populasi yang ukurannya besar.

Sugiyono (2017:63), Non-probability sampling sangat tepat digunakan untuk teknik pengambilan sampel dimana untuk menentukan sampel memerlukan spesifikasi tertentu untuk diambil sebagai sampel.

Teknik pengambilan sampel yang saya gunakan yakni sampling purposive ,yang termasuk dalam kategori non-probability sampling. Sugiyono (2017:68) Sampling Purposive artinya melakukan pengambilan sampel dengan kriteria yang diinginkan penulis, agar hasil penelitian bisa efektif.

\section{Jenis dan Sumber Data}

Penelitian yang saya lakukan menggunakan data sekunder yang mana berbentuk dokumen yang diperoleh secara tidak langsung dari perusahaan, dan secara kuantutatif yang berbentuk angka-angka

Arikunto (2018:144), Sumber Data bisa diperoleh dari subjek yang berhubungan dengan data yang ingin digunakan untuk melakukan penelitian.

Sumber data dari penelitian saya berasal dari BEI, yang mana terdapat data-data yang sesuai dengan yang saya inginkan untuk penelitian ini.

\section{Teknik Pengumpulan Data}




\section{Journal of Sustainability Business Research (JSBR)}

\section{Vol-1,Issue-1,Desember (JSBR)}

\section{E-ISSN: 2746-8607}

http://jurnal.unipasby.ac.id/index.php/jsbr

Teknik pengumpulan data yang digunakan dalam penelitian ini dengan melakukan analisa pada laporan keuangan perusahaan BUMN secara langsung.

\section{Variabel Penelitian dan Definisi Operasional Variabel}

Sugiyono (2017:66) Variabel penelitian pada dasarnya membuat peneliti mempelajari apa saja hal bisa dijadikan infromasi untuk ditarik kesimpulan. Terdapat 2 variabel yang umum digunakan, yaitu variabel bebas atau penyebab adanya variabel terikat, sedangkan variabel terikat adalah akibat dari adanya variabel bebas.

Dari penjelasan mengenai variabel diatas, bisa saya simpulkan bahwa penelitian ini menggunakan dua variabel, yakni variabel bebas ( CTO, DAR, ATO, ROA, dan PER ) dan variabel terikat ( Harga Saham ) Definisi operasional yang saya gunakan dalam penelitian ini adalah:

1. Kasmir (2016:160), CTO (Cash Turn Over) digunakan untuk mengetahui apakah modal kerja yang ada bisa dipakai untuk menutupi tagihan-tagihan yang ditujukan untuk perusahaan. Rumus untuk perhitungan CTO adalah:

$$
C=\frac{P}{R}-r_{1} \quad K \quad h
$$

2. Kasmir (2016:156), DAR (Debt to Asset Ratio) digunakan agar perusahaan mampu menutupi hutang yang ada dengan melihat jumlah aktiva yang ada. Rumus untuk perhitungan CTO adalah:

$$
D=\frac{T H}{T \cdot A}
$$

3. Agus Sartono (2014:120), ATO (Asset Turn Over) digunakan untuk mengetahui seberapa baik sebuah perusahaan dalam menggunakan aset untuk menghasilkan keuntungan. Rumus untuk perhitungan ATO adalah:

$$
A=\frac{P}{T A} A
$$

4. Eduardus Tandelilin (2017:372), ROA (Return on Assets) memiliki arti jika aset sebuah perusahaan bisa digunakan untuk mengukur pencapaian laba yang akan dihasilkan nantinya. Rumus untuk perhitungan ROA adalah:

$$
R=\frac{L \quad B \quad h S \quad h P}{T \quad A}
$$

5. Irham Fahmi (2015:67), PER (Price Earning Ratio) digunakan untuk mengetahui kenaikan laba yang diperoleh dari setiap lembar saham dan membandingkannya dengan harga pasar per lembar saham. Rumus untuk perhitungan PER adalah:

$$
P=\frac{H \quad S h a}{E}
$$

\section{Teknik Analisis Data}

Karena penelitian ini merupakan penelitian kuantitatif maka teknik analisis yang digunakan menggunakan metode kuantitatif juga tentunya. Dengan demikian saya menggunakan beberapa metode analisis serta uji hipotesis seperti dibawah ini :

1. Uji Asumsi Klasik

a. Uji Normalitas

Ghozali (2016:154), uji normalitas digunakan untuk mengetahui apakah antar variabel telah terdistribusi normal ataukah tidak.

b. Uji Multikolinearitas

Ghozali (2016:103), uji multikolinearitas digunakan untuk menemukan adanya korelasi antar variabel bebas,

c. Uji Heterokedastisitas 


\section{Journal of Sustainability Business Research (JSBR)}

Vol-1,Issue-1,Desember (JSBR)

\section{E-ISSN: 2746-8607}

http://jurnal.unipasby.ac.id/index.php/jsbr

Ghozali (2016:134), uji heterokedastisitas digunakan untuk menemukan apakah antar variabel terdapat varians yang berbeda ataukah tidak.

d. Uji Autokorelasi

Ghozali (2016:107), uji autokorelasi terjadi akibat adanya kaitan antar observasi yang berurutan.

2. Uji Regresi Linear Berganda

Sugiyono (2017:275), Regresi Linear Berganda hanya bisa dilakukan apabila penelitian menggunakan minimal 2 variabel, dimana uji ini digunakan untuk mengetahui tingkatan variabel itu sendiri.

3. Koefisien Determinasi

Sugiyono (2017:232), Koefisien Determinasi adalah hasil dari koefisien korelasi yang dikuadratkan, dan hasil varians yang didapat akan menjadi penentu.

4. Uji T

Afrizal (2017:608), Uji ini dilakukan untuk mengetahui pengaruh variabel bebas terhadap variabel terikat secara parsial. Ghozali (2016:99), untuk mengambil keputusan ditetapkan apabila nilai p kurang dari 0,05 maka hipotesis yang diajukan diterima, dan juga sebaliknya apabila nilai $p$ lebih dari 0,05 maka hipotesis yang diajukan ditolak.

5. Uji F

Jika uji t untuk mengetahui pengaruh secara parsial antar variabel maka uji f digunakan untuk mengetahui pengaruh antar variabel secara simultan. Ghozali (2016:99), untuk mengambil keputusan ditetapkan apabila nilai $p$ kurang dari 0,05 atau f hiyung lebih dari sama dengan $f$ tabel maka hipotesis yang diajukan diterima, dan juga sebaliknya jika nilai $p$ lebih dari sama dengan 0,05 maka hipotesis yang diajukan ditolak.

\section{HASIL}

Berikut adalah hasil dari beberapa uji yang telah dilakukan:

1. Uji Asumsi Klasik

a. Uji Normalitas

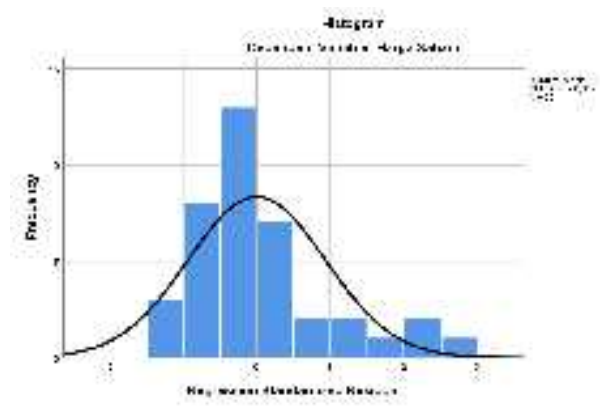

Gambar 2. Histogram

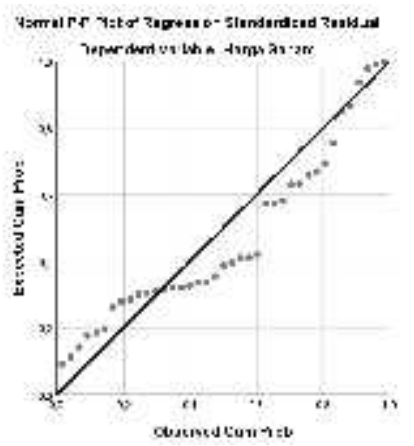




\section{Journal of Sustainability Business Research (JSBR)}

Vol-1,Issue-1,Desember (JSBR)

\section{E-ISSN: 2746-8607}

http://jurnal.unipasby.ac.id/index.php/jsbr

Gambar 3. Normal P-Plot

Dari hasil histogram menunjukkan bahwa penelitian mendekati normal, sedangkan dari p-plot menunjukkan bahwa titik-titik mengikuti garis diagonal. Dengan demikian dapat disimpulkan bahwa data terdistribusi normal karena tidak menyalahi aturan bahwa model regresi yang baik yakni distribusi normal atau mendekati normal.

b. Uji Multikolinearitas.

Coefficients ${ }^{1}$

\begin{tabular}{|c|c|c|c|}
\hline \multirow[b]{2}{*}{ Mcdel } & & \multicolumn{2}{|c|}{ Lolineanty Statistocs } \\
\hline & & Toleranre: & VIF \\
\hline 1 & CTO & 0.377 & 2,600 \\
\hline & DAR & 0.608 & 1.643 \\
\hline & ATO & 0,356 & 2,808 \\
\hline & $70 \AA$ & 0.626 & 1,508 \\
\hline & PFR & 0,920 & 1,127 \\
\hline
\end{tabular}

\section{Gambar 4. Coefficients}

Dari tabel diatas menunjukkan bahwa tidak ada variabel bebas yang memiliki nilai tolerance kurang dari 0,10 yakni CTO $(0,371)$, DAR $(0,608)$, ATO $(0,356)$, ROA $(0,626)$, dan PER $(0,920)$. Dengan demikian penelitian terbebas dari masalah multikolinearitas karena tidak ada yang terdapat korelasi.

c. Uji Heterokedastisitas

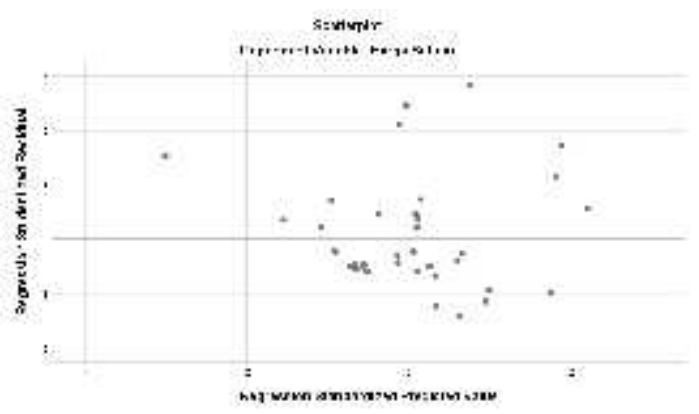

Gambar 5. Scatter Plot

Dari gambar scatter plot menunjukkan bahwa titik-titik menyebar, tidak membentuk pola tertentu dan juga menyebar diatas maupun dibawah nilai 0 pada sumbu Y. Dengan demikian tidak terdapat masalah heterokedastisitas sehingga memenuhi syarat untuk uji regresi.

d. Uji Autokorelasi 
Journal of Sustainability Business Research (JSBR)

Vol-1,Issue-1,Desember (JSBR)

\section{E-ISSN: 2746-8607}

http://jurnal.unipasby.ac.id/index.php/jsbr

\begin{tabular}{|c|c|}
\hline Runs & $\begin{array}{l}\text { Unsiandardized } \\
\text { Residual }\end{array}$ \\
\hline Tast Valuent & $-832,42742$ \\
\hline Cases < Test Value & 17 \\
\hline Cases >- Test Value & 22 \\
\hline Total Cases & 39 \\
\hline Number of Runs & 15 \\
\hline$z$ & $-1,62$ \\
\hline $\begin{array}{l}\text { Asurto. Sig. (2-tailedi } \\
\text { if Meatian }\end{array}$ & 0,105 \\
\hline
\end{tabular}

\section{Gambar 6. Runs Test}

Dari hasil uji Runs Test menujukkan bahwa Asymp. (2-tailed) sebesar 0,105 yang mana 0,105>0,05. Dengan demikian dapat disimpulkan bahwa tidak terdapat masalah autokorelasi, sehingga dapat dinyatakan lolos uji autokorelasi.

2. Uji Regresi Linear Berganda

\begin{tabular}{lc} 
& $\begin{array}{c}\text { ('nefficients } \\
\text { Coefflclents }\end{array}$ \\
\hline Model & \multicolumn{1}{c}{ B } \\
\hline (Constant) & $-1004,720$ \\
CTO & $-1616,996$ \\
DAR & 5351,948 \\
ATO & 11314,072 \\
ROA & 138,007 \\
PER & $-1,050$
\end{tabular}

a. Dependent Variable: Harga Saham

Gambar 7. Regresi Berganda

Dari gambar diatas diperoleh hasil persamaan regresi linear berganda sebagai berikut:

Harga Saham $=-1004,720+(-1616,996)+5351,948+11314,072+138,007+(-1,050)$

Konstan sebesar -1004,720 menujukkan nilai harga saham, jika tidak ada CTO, DAR, ATO, ROA, dan PER, harga saham berikutnya menurun sebesar $-1004,720$.

3. Koefisien Determinasi

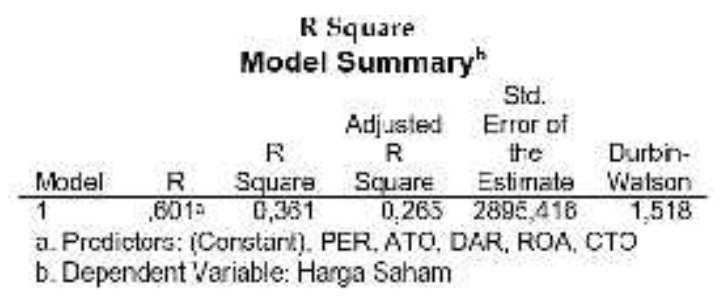

Gambar 8. Determinasi

Berdasarkan gambar diatas dapat disimpulkan bahwa nilai koefisien determinasi $\left(k^{2}\right)$ secara simultan adalah sebesar 0,361 atau berarti 36,1\% variabel harga saham dipengaruhi oleh CTO, DAR, ATO, ROA, dan PER. Sedagkan sisanya sebesar $63,9 \%$ dipengaruhi oleh variabel lain yang tidak terdapat dalam penelitian ini. Dari nilai $R$ sebesar 0,601 mengindikasikan bahwa hubunagn CTO, DAR, ATO, ROA, dan PER terhadap harga saham dikatakan cukup kuat.

4. Uji T 
Journal of Sustainability Business Research (JSBR)

Vol-1,Issue-1,Desember (JSBR)

\section{E-ISSN: 2746-8607}

http://jurnal.unipasby.ac.id/index.php/jsbr

\begin{tabular}{llll} 
& \multicolumn{3}{c}{ Coefficients $^{3}$} \\
Variabel & $\mathrm{t}$ & Sig. & Kelerangan \\
\hline CTO & $-3,611$ & 0,001 & Signifikan \\
DAR & 1,574 & 0,125 & Tidak Signifikan \\
ATO & 4,002 & 0,000 & Signifikan \\
ROA & 1,175 & 0,248 & Tidak Signifikan \\
PER & $-0,460$ & 0,649 & Tidak Signifikan \\
\hline
\end{tabular}

a. Dependent Variable: Harga Saham

\section{Gambar 9.Uji T}

Dari tabel diatas menunjukkan hasil uji secara parsial dimana 2 dari 5 variabel bebas yang digunakan menunjukkan pengaruh signifikan terhadap harga saham sedangkan 3 lainnya tidak berpengaruh secara siginifikan. Dengan demikian CTO dan ATO mempengaruhi harga saham, sedangkan DAR, ROA, dan PER tidak mempengaruhi harga saham

\section{Uji F}

\begin{tabular}{|c|c|c|c|c|c|}
\hline \multicolumn{6}{|c|}{ ANOVA" } \\
\hline $\begin{array}{l}\text { Model } \\
1\end{array}$ & I'egrassion & $\frac{d t}{5}$ & $\begin{array}{l}\text { Mean Square } \\
3131197 /, 423\end{array}$ & $\begin{array}{c}\mathrm{F} \\
3,735\end{array}$ & $\begin{array}{l}519 \\
603=\end{array}$ \\
\hline & Residual & $3 z$ & 8383431,632 & & \\
\hline & Totsl & 38 & & & \\
\hline
\end{tabular}

Gambar 10. Uji F

Dari hasil anova menunjukkan nilai f hitung sebesar 3,735 dan nilai signifikan sebesar 0,009 sehingga $0,009<0,05$. Dari hasil tersebut dapat dinyatakan bahwa CTO, DAR, ATO, ROA, dan PER

\section{SIMPULAN} berpengaruh secara simultan terhadap harga saham.

Setelah dilakukan serangkaian uji untuk menunjukkan hasil yang signifikan. Maka saya dapat menyimpulkan bahwa dari 6 hipotesis yang diajukan terdapat beberapa yang ditolak dan beberapa yang diterima.

Untuk secara parsial CTO dan ATO ternyata membuktikan bahwa variabel ini mempengaruhi harga saham perusahaan BUMN secara signifikan. Sedangkan DAR, ROA, dan PER menyatakan hasil bahwa variabel ini tidak mempengaruhi harga saham perusahaan BUMN,

Secara simultan hasil uji menunjukkan bahwa CTO, DAR, ATO, ROA, dan PER dapat mempengaruhi harga saham perusahaan secara signifikan. Dengan nilai signifikan sebesar 0.009 dan $f$ hitung sebesar 3,375. Maka dari itu hipotesis ini diterima.

\section{IMPLIKASI}

Hasil penelitian ini selanjutnya dapat digunakan oleh pemegang kebijakan perusahaan BUMN yang terkait dengan penelitian ini sebagai bahan pertimbangan dalam melakukan investasi terutama mengenai saham untuk prospek kedepannya.

\section{KETERBATASAN PENELITIAN}

Dengan dituliskannya artikel ini, maka peneliti mengetahui akan beberapa kekurangan yang tentunya membuat penelitian ini sedikit sulit dilakukan, namun pada akhirnya tetap dapat terselesaikan dengan baik. Keterbatasan terletak pada perbedaan angka digit pada masing-masing perusahaan yang berbedabedasatu sama lain. Sehingga perlu dikonversi sama rata agar penelitian ini bisa ditulis dengan baik dan sesuai, 


\section{Journal of Sustainability Business Research (JSBR)}

Vol-1,Issue-1,Desember (JSBR)

E-ISSN: 2746-8607

http://jurnal.unipasby.ac.id/index.php/jsbr

\section{DAFTAR PUSTAKA}

Arikunto, Suharsimi, 2018, Prosedur Penelitian: Suatu Pendekatan Praktik. Edsisi Revisi. Penerbit: Rineka

Cipta. Jakarta

Fahmi, Irham, 2015, Pengantar Pasar Modal. Penerbit: Alfabeta. Bandung

Hadi, Nor, 2015, Pasar Modal. Edisi 2. Penerbit: Yoga Pratama. Semarang

Hartono, Jogiyanto, 2017, Toeri Portofolio dan Analisis Investasi. Edisi 11. Penerbit: BPFE. Yogyakarta

Kasmir, 2015, Studi Kelayakan Bisnis. Edisi Revisi. Penerbit: Divisi Kencana Prenada Media Group. Jakarta

Kasmir, 2016, Pengantar Manajemen Keuangan. Penerbit: Divisi Kencana Prenada Media Group. Jakarta Margono, S, 2014, Metodologi Penelitian Pendidikan. Penerbit: Rineka Cipta. Jakarta

Miradji, M.A (2017), Analisis Risiko Pengelolaan Perputaran Kas dan Perputaran Piutang Terhadap

Likuiditas (Study Kasus Koperasi Anas Surabaya), pp. 604-615

Munawir, S, 2014, Analisa Laporan Keuangan. Cetakan ke 15. Penerbit: Liberty. Yogayakarta

Samryn, L.M, 2015, Akuntansi Manajemen. Edisi Revisi. Penerbit : Divisi Kencana Prenada Media Group. Jakarta

Sartono, Agus, 2014, Manajemen Keuangan: Teori dan Aplikasii. Edisi 4. Penerbit: BPFE. Yogyakarta

Sugiyono, 2017, Metode Penelitian Bisnis. Edisi 3. Penerbit: Alfabeta. Bandung

Sugiyono, 2017, Statistika untuk Peneltian. Cetakan ke 28. Penerbit: Alfabeta. Bandung

Tandelilin, Eduardus, 2017, Pasar Modal: Manajemen Portofolio dan Investasi. Penerbit: BPFE UGM.

Yogyakarta 